\title{
Introduction and preparation of an objective structured clinical examination in family medicine for undergraduate students at the University of Split
}

\author{
Irena Zakarija-Grković1, Vladimir Šimunović
}

\author{
${ }^{1}$ University of Split School of Medicine \\ Department of Family Medicine \\ Split, Croatia \\ ${ }^{2}$ University of Split School of Medicine \\ Department of Medical Humanities \\ Split, Croatia \\ Corresponding author: \\ Irena Zakarija-Grković \\ Department of Family Medicine \\ University of Split School of Medicine \\ Šoltanska 2 \\ Split 21000 \\ Croatia \\ irena.zakarija-grkovic@mefst.hr \\ Tel.: + 38521557823 \\ Fax: + 38521557895
}

Received: 22 December 2011

Accepted: 27 March 2012

Copyright (C) 2012 by

Academy of Sciences and Arts

of Bosnia and Herzegovina.

E-mail for permission to publish:

amabih@anubih.ba

\begin{abstract}
Objective. To describe the implementation of the first Objective Structured Clinical Examination (OSCE) conducted at the University of Split School of Medicine. Methodology. Twenty-one clinical skills relevant to general practice were selected and described in a Handbook for students. Assessment sheets were created. After performing an inventory of available resources, teaching models were purchased and practical classes arranged. A Centre for Clinical Competencies was established, where the first OSCE at the University of Split School of Medicine was conducted in March 2011. Results. Attendance by students to the practical classes and the OSCE was 100\%. Positive feedback was received by students, who requested extra lessons in clinical skills training. Despite not setting a minimal pass rate, the average OSCE score was 27 out of 30 points. Conclusion. Organization of clinical skills training and assessment was demanding, requiring many hours of preparation and numerous staff involvement but was ultimately very rewarding. Both practical classes and the OSCE were very well received by students, who seemed to be empowered by this experience.
\end{abstract}

Key words: Medical education, Clinical skills, Assessment, Objective structured clinical examination.

\section{Background}

The objective structured clinical examination (OSCE) was first described by Harden in 1975 as, 'a timed examination in which medical students interact with a series of simulated patients in stations that may involve history-taking, physical examination, counseling or patient management' (1). This novel form of examination was introduced with the aim of avoiding many of the disadvantages of the traditional clinical examination (2); lack of impartiality and inadequate access to patients in any given moment being the most important among them.

There are a number of advantages in the OSCE approach. First, in the traditional clinical examination there are several variables: (i) the student; (ii) the patient and (iii) the 
examiner. In the structured clinical examination there are only two variables: the patient and the examiner. These are more controlled and hence a more objective assessment of the student's clinical competence is possible. Second, the complexity of the OSCE is easier to determine, therefore it is possible to more clearly define what skills, attitudes, problemsolving abilities, and factual knowledge are to be assessed. Third, the examination is more easily repeatable than the traditional clinical exam and standards from year to year may be more easily compared (1). Finally, the marking strategy for the examination may be decided by the examiners in advance, it is unique for all stations and for all examiners, making it as objective as it can be.

The main disadvantage is that more laborious preparation is required. As with many educational advances the benefits are achieved in part by more effort. This effort, however, takes place before the examination, and on the day of the examination the examiner's time is used more efficiently. The cost of conducting the examination is another important issue (3). Another possible disadvantage of this approach may be the feeling that the student's knowledge and skills are being put into compartments and that he/she is being discouraged from looking at the patient as a whole. Finally, if patients are to be involved during the examination, they must be selected carefully to minimize disturbance and discomfort for the patient.

A number of authors have described the conceptualization and measurement of clinical competence through the use of OSCEs. They define this form of competence as a psychological construct that includes aspects of cognitive, affective, psychomotor skills such as critical thinking and problem-solving, and the incorporation of knowledge, values, beliefs, and attitudes. The OSCE has been found to be a reliable form of assessment in undergraduate, postgraduate and in nursing education (4-10).
Additionally, OSCEs have been shown to be feasible and have good reliability and validity $(11,12)$ and their use has become widespread for performance-based assessment, particularly in undergraduate examinations. At the University of Split School of Medicine, OSCE was integrated as an important component of our new paradigm of clinical skills teaching, both in medical and nursing education (13-16).

The University of Split School of Medicine, one of four medical faculties in Croatia, was established in 1997 (17) and is located in the industrial and cultural centre of Southern Croatia - Split. The School's Department of Family Medicine currently has 35 staff members: one is a full-time research fellow and the rest are employed part-time in various roles. Family medicine is, like all other subjects, organized in teaching blocks and during this period (January to March) all staff members are involved in teaching sixth year medical students.

The first OSCE to be held at the University of Split School of Medicine was organized by the Department of Family Medicine for sixth year medical students as part of their final assessment.

In this article we describe the practical steps required to successfully implement an OSCE, based on our experience.

\section{Methods \\ Participants}

Fifty-four medical students enrolled into their sixth year of studies for the academic year 2010/2011.

\section{Preparation}

The first task was to compile a list of clinical skills that satisfied the following criteria: (i) important for general practice; (ii) can be tested in laboratory settings; (iii) executable within 5 minutes and (iv) can be demonstrated without oral questioning by the 
examiner/observer. Discussions at Departmental meetings resulted in a list of 21 clinical skills (Table 1).

A working group undertook the responsibility of preparing the written materials and organizing practical classes in order to prepare the students for this new form of assessment. Each clinical skill was described

Table 1 List of eligible clinical skills

\begin{tabular}{ll}
\hline No. & Clinical Skill \\
\hline 1. & Arterial blood pressure measurement \\
2. & Setting up an IV infusion set \\
3.- 6. & Intramuscular /intravenous/subcutaneous/ \\
& intradermal drug administration \\
7. & Transurethral catheterization (male and \\
8. & Bemale) \\
9. & Examination for meningeal signs \\
10. & Palpation of peripheral arteries \\
11. & Immobilization \\
12. & Intubation \\
13. & Managing anaphylactic shock \\
14. & Digitorectal examination \\
15. & Recording an ECG \\
16. & Removal of sutures \\
17. & Administration of oxygen therapy \\
18. & Execution of Heimlich's manoeuvre \\
19. & Insertion of oropharyngeal mouthpiece \\
20. & Basic life support \\
21. & Sterile gloving \\
\hline
\end{tabular}

in detail, based on the latest available guidelines. Once completed and reviewed by all departmental members, these instructions, supported by illustrations and references, were posted, in the form of a Handbook, on the Department's web site, to facilitate student access.

Next, appropriate scoring forms were devised for each of the clinical skills (Table 2).

For each skill, a clearly specified task (e.g. measure arterial blood pressure using a sphygmomanometer) was set, and divided into a sequence of six logical steps. Each step carried one point, earning the student a total of 6 points per skill, if executed correctly. These scoring forms served as criteria for the observers/assessors during the OSCE. For each clinical skill, summary assessment sheets were used to enter whether the students "performed/did not perform" an individual step (Table 3 ).

Some educational institutions add a third assessment option expressed as "partially executed" (18). In our opinion, this just complicates the final score unnecessarily. A minimal passing rate for the OSCE was not set; instead, the total number of points obtained contributed to the student's final grade in family medicine.

Here it should be underlined that there is no gold standard for scoring and marking OSCEs. Each method has its advantages and disadvantages. However, it is vital that the

Table 2 Scoring form for blood pressure measurement

\begin{tabular}{|c|c|c|c|}
\hline Step & Description & Performed & Not performed \\
\hline 1 & Patient appropriately prepared for blood pressure measurement. & & \\
\hline 2 & $\begin{array}{l}\text { Appropriate cuff selected (length, width) and placed correctly on arm }(2-3 \mathrm{~cm} \\
\text { above cubital fossa). } \\
\text { Arm positioned at the level of the heart. }\end{array}$ & & \\
\hline 3 & Radial artery palpated and level of disappearance of pulse determined. & & \\
\hline 4 & Stethoscope correctly placed over brachial artery. & & \\
\hline 5 & Cuff inflated and gradually deflated at a rate of $1-2 \mathrm{~mm} / \mathrm{s}$. & & \\
\hline 6 & $\begin{array}{l}\text { Procedure repeated twice. } \\
\text { Average value of arterial blood pressure recorded. }\end{array}$ & & \\
\hline
\end{tabular}


Table 3 Sample summary assessment form for an individual station (clinical skill)

\begin{tabular}{|c|c|c|c|c|c|c|c|}
\hline \multicolumn{8}{|c|}{ Station A: Measuring blood pressure } \\
\hline Student No. & Step 1 & Step 2 & Step 3 & Step 4 & Step 5 & Step 6 & Total points \\
\hline \multicolumn{8}{|l|}{1} \\
\hline \multicolumn{8}{|l|}{2} \\
\hline \multicolumn{8}{|l|}{3} \\
\hline \multicolumn{8}{|l|}{4} \\
\hline \multicolumn{8}{|l|}{5} \\
\hline \multicolumn{8}{|l|}{6} \\
\hline \multicolumn{8}{|l|}{7} \\
\hline \multicolumn{8}{|l|}{8} \\
\hline \multicolumn{8}{|l|}{9} \\
\hline $10 \ldots$ & & & & & & & \\
\hline
\end{tabular}

marking process used is feasible and transparent, and produces defensible outcomes. The ultimate aim of any method used for OSCE scoring and marking is to ensure a consistent and equitable assessment of students' OSCE performances, which uniformly rewards them for demonstrating advanced clinical practice competence.

Once the written material was completed, we set out to find/purchase the models and materials required for the practical classes and OSCE. An inventory of all the available equipment was made and a list of necessary materials forwarded to faculty management. This list was based upon individual lists of necessary equipment compiled for each clinical skill. Once the required equipment had been assembled, staff members met and timed the execution of all 21 clinical skills in order to check that they could be performed within five minutes.

\section{Clinical skills classes}

To enable the students to learn the selected clinical skills, five 2- hour practical classes were incorporated into the students' timetable, envisaging approximately 10 students per group. Immediately prior to each class, the models had to be transferred from the storeroom to the allocated classroom, set- up and returned afterwards, which proved to be quite cumbersome. Instructions for each clinical skill were placed beside the model and students were advised to practice in pairs, taking turns reading the instructions and performing the clinical skill. The students were supervised by a clinical skills instructor, familiar with all the models and accompanying written material. The use of dispensable materials (suturing material, lubricant, needles, gloves...) was noted and new supplies obtained. Students were surveyed for their opinion of the new classes.

During the teaching period it became obvious that a room allocated for practicing clinical skills was necessary, where models could be permanently displayed and available for use by all students. With the support of the faculty management, a facility with four rooms and large lobby was identified, renovated and equipped with clinical teaching materials, resulting in establishment of the faculty's Centre for Clinical Competencies- a permanent facility designed for ongoing utilization in teaching and practicing clinical skills and for conducting examinations. We believe that this was a crucial step in setting up OSCEs as a standard form of assessment at the University of Split School of Medicine. 


\section{The objective structured clinical examintation}

The logistics of conducting the OSCE were complex. In order to minimize student waiting time, increase staff commitment and prevent the leakage of information, we had to anticipate a number of important factors, including the number of students attending the examination, the availability of classrooms and the availability of staff. Since it was our first attempt at organizing an OSCE, it was decided that only 5 clinical skills would be tested. The final choice was made by the head of the department immediately prior to the exam.

An exam timetable was drawn up based on 5 , five minute clinical skills demonstrations or 'stations', including a one minute interval for students to get from one station to another and for observers to set up their station (Table 4).

Two OSCE teams were formed - one for the a.m. shift and the second for the p.m. shift. Each of the teams was composed of an invigilator, chaperone, timer/bell-ringer, observer for each clinical skill and a circulating person. Each team met once to familiarize themselves with the exam procedure and was provided with written material, including information sheets, scoring forms, a list

Table 4 Section of OSCE timetable

\begin{tabular}{llllll}
\hline \multirow{2}{*}{ Time } & \multicolumn{3}{l}{ Stations } & & \\
\cline { 2 - 6 } & A & B & C & D & E \\
\hline $10: 00-10: 06$ & 1 & & & & \\
$10: 06-10: 12$ & 2 & 1 & & & \\
$10: 12-10: 18$ & 3 & 2 & 1 & & \\
$10: 18-10: 24$ & 4 & 3 & 2 & 1 & \\
$10: 24-10: 30$ & 5 & 4 & 3 & 2 & 1 \\
$10: 30-10: 36$ & 6 & 5 & 4 & 3 & 2 \\
$10: 36-10: 42$ & 7 & 6 & 5 & 4 & 3 \\
$10: 42-10: 48$ & 8 & 7 & 6 & 5 & 4 \\
$10: 48-10: 54$ & 9 & 8 & 7 & 6 & 5 \\
$10: 54-11: 00 \ldots$ & 10 & 9 & 8 & 7 & 6 \\
\hline
\end{tabular}

of students, and exam assessment sheets. The exam assessment sheet enabled quick and easy documentation of each student's performance.

On March $1^{\text {st }}$ the first OSCE at the University of Split School of Medicine was conducted. Students were gathered in a lecture theatre where, after handing in their mobile phones and receiving instructions, they were accompanied in groups of five to the examination area. With each announcement of the timer/bell-ringer students rotated through the five stations which consisted of the following clinical skills: hand washing, gloving, intramuscular drug administration, palpation of peripheral pulses of the lower extremities and blood pressure measurement. On completion of the examination, students were asked for their impressions, after which they gathered their belongings and were escorted out of the building.

\section{Results and Discussion}

Attendance by students to practical classes was $100 \%$. Feedback from students was very positive and included comments such as "I feel like a real doctor now", "I wish there were more of these classes", " why hasn't this been done before?" and "it's great being able to practice these skills without worrying about the patient". As a result of students' expressed need, two additional 2-hour practical classes were organized. An obvious increase in student self-confidence and competence in performing clinical skills was noted by the instructors.

All final year medical students attended the OSCE- fifty-four in total. After completing the OSCE, verbal comments from students were very positive, including "It was fun", "That was much better than I expected" and "I feel a lot more secure in my clinical competencies now". Students averaged 27 out of a total of 30 points for the five clinical skills assessed. 
There were several limitations to our approach in conducting the OSCE in family medicine. First, the last students on the alphabetical list had to wait several hours before being examined. Based on this experience, we plan to divide the students into two groups in the future to keep waiting time to a minimum. Second, the allocated time interval for our stations was too long; 3 minutes would have sufficed, with one minute for change of stations. Third, one station (i.m. injection) lasted considerably longer than two other stations (hand washing and gloving) located in the same room, resulting in students overhearing other student's responses. Finally, there was some minor discrepancy in assessment techniques between observers in the a.m. and p.m. shift, necessitating standardization of some results.

\section{Conclusion}

The provision of time and a place for students to practice clinical skills taught during their undergraduate training should be standard practice in all medical schools, whilst at the same time not endangering the health of patients. These acquired competencies can be objectively assessed using the OSCE model. This was organized, for the first time at the University of Split School of Medicine, in March 2011 by the Department of Family Medicine for final year medical students. Both practical classes and the OSCE were very well received by students, who seemed to be empowered by this experience. Organization of practical classes and the OSCE was demanding requiring many hours of preparation and numerous staff involvement but was ultimately very rewarding. OSCEs are an objective and standardized method of assessment.

Acknowledgement: We would like to thank Dr. Ivančica Pavličević for her encouragement as Head of the Department, Prof. Mirjana Rumboldt for critically reviewing the Handbook, Prof. Matko Marušić for his support as Dean, and all the Department of Family
Medicine staff members involved in organizing our first OSCE.

Authors' contributions: Concept and design: IZG and VS; Drafting and final approval of the article: IZG and VS.

Conflict of interest: The authors declare that they have no conflict of interest. This article was not sponsored by any external organisation.

\section{References}

1. Harden RM, Stevenson M, Downie WW, Wilson GM. Assessment of Clinical Competence using Objective Structured Examination. Br Med J. 1975;1:447-51.

2. Harden RM, Gleeson FA. Assessment of clinical competence using an objective structured clinical examination (OSCE). Med Educ. 1979;13(1):41-54.

3. Cusimano MD, Cohen R, Tucker W, Murnaghan J, Kodama R, Reznick R. A comparative analysis of the costs of administration of an OSCE (objective structured clinical examination). Acad Med. 1994;69(7):571-6.

4. Martin IG, Jolly B. Predictive validity and estimated cut score of an objective structured clinical examination (OSCE) used as an assessment of clinical skills at the end of the first clinical year. Med Edu. 2002;36:418-25.

5. Matsell DG, Wolfish NM, Hsu E. Reliability and validity of the objective structured clinical examination in paediatrics. Med Edu. 1991;25(4):293-9.

6. McGaughey J. Standardizing the assessment of clinical competence: an overview of intensive care course design. Nurs Critic Care. 2004;9(5):238-46.

7. Schwartz RW, Witzke DB, Donnelly MB, Stratton T, Blue AV, Sloan DA. Assessing residents' clinical performance: cumulative results of a four-year study with the objective structured clinical examination. Surgery. 1998;124(2):307-12.

8. Selby C, Osman L, Davis M, Lee M. Set up and run an objective structured clinical exam. Br Med J. 1995;310(6988):1187.

9. Townsend AH, Mcllvenny S, Miller CJ, Dunn EV. The use of an objective structured clinical examination (OSCE) for formative and summative assessment in a general practice clinical attachment and its relationship to final medical school examination performance. Med Edu. 2001;35:841-6.

10. Watson R, Stimpson A, Topping A, Porock D. Clinical competence assessment in nursing: a systematic review of the literature. J Adv Nurs. 2002;39(5):421-31. 
11. Verhoeven BH, Hamers JGHC, Scherpbier AJJA, Hoogenboom RJI, van der Vleuten GPM. The effect on reliability of adding a separate written assessment component to an objective structured clinical examination. Med Edu. 2000;34:525-9.

12. Hodges B, Regehr G, Hanson M, McNaughton $\mathrm{N}$. Validation of an objective structured clinical examination in psychiatry. Acad Med. 1998 ;73(8):910-2.

13. Šimunović F, and Šimunović VJ. Training Clinical Skills in 20th and 21st century: Two Generations and Two Worlds Apart. Part One. Acta Medica Academica. 2009;38:70-6.

14. Šimunović F, and Šimunović VJ. Training Clinical Skills in 20th and 21st century: A New Paradigm. Part Two. Acta Medica Academica. 2010:39; 45-55.

15. Šimunović VJ, Hozo I, Rakić M, Jukić M, Tomić S, Kokić S, et al. New Paradigm in Training of
Undergraduate Clinical Skills: the NEPTUNE-CS project at the Split University School of Medicine. Croat Med J. 2010;51:373-80.

16. Šimunović VJ, Županović M, Mihanović F, Bradarić N, Janković S. In search of a Croatian Model of nursing education. Croat Med J. 2010; 51: 383-95.

17. Marusic M. History of School of Medicine in Split [in Croatian]. In: Jankovic S, Boban M, editors. University of Split, School of Medicine, 19972007. Split: University of Split, School of Medicine; 2007. p. 16-35.

18. Wilkinson T, Newble D, Frampton C. Standard setting in an objective structured clinical examination: use of global ratings of borderline performance to determine the passing score. Med Educ. 2001;35(11):1043-9. 